\title{
EMOÇÕES E POLÍTICA: A VÍTIMA E A CONSTRUÇÃO DE COMUNIDADES EMOCIONAIS *
}

Myriam Jimeno

\section{Apresentação}

Detenho-me, neste texto, na construção cultural da categoria de vítima ${ }^{1}$ como forma de afirmação da civilidade. Ao longo dos últimos anos, temos presenciado na Colômbia a afirmação de uma linguagem que narra experiências pessoais de sofrimento na forma de testemunho pessoal. Essa linguagem, eminentemente emocional, cria laços entre pessoas diversas, naquilo que podemos chamar sociedade civil, ao redor do compartilhamento da "verdade" a respeito dos fatos de violência ocorridos recentemente. Argumento que essa linguagem do testemunho pessoal tem efeitos políticos, na medida em que constrói uma versão compartilhada dos acontecimentos de violência da última década e serve de alicerce para uma ética do reconhecimento e para ações de protesto e de reparação, visto que é um mediador simbólico entre a experiência subjetiva e a generalização social. A natureza emocional dessa categoria torna possível, como nunca antes no país, tecer vínculos de identidade e reconhecimento entre aqueles que experimentaram a violência e o conjunto da população civil. Esses vínculos são expressos publicamente sob a forma de encenações, mobilizações e imagens compartilhadas. Assim, a linguagem do testemunho pessoal conforma comunidades no sentimento, por mim chamadas de comunidades emocionais, de moralidade, fundadas numa ética do reconhecimento. A categoria de vítima é, portanto, o decantado simbólico e o ponto de confluência desse processo de reconhecimento. Essa categoria permite ventilar, de maneira inédita na Colômbia, os fatos de violência pela ótica dos que a sofreram.

Examino a construção social da categoria de vítima em três cenários sociais: a ação pública de uma comunidade indígena, as manifestações massivas dos últimos anos, em especial em 2008, e a luta pela promulgação da Lei de Vítimas. 


\section{Kitek Kiwe, comemorações}

Em abril do ano passado assisti pela primeira vez à comemoração do aniversário do massacre cometido pelos chamados paramilitares no alto rio Naya $^{2}$ em 2001. Chamou-me a atenção que, nas semanas anteriores à comemoração, uma pequena comunidade de deslocados sobreviventes desse massacre, junto à qual faço pesquisa, estivesse febrilmente dedicada a preparar o evento. Ali eles seriam, na realidade, apenas uma das tantas organizações participantes que iriam até o pequeno povoado de Timba, porta de entrada do Naya pelo Vale do Cauca. Estariam presentes, em primeiro lugar, o delegado da Comissão Nacional de Reparação e representantes da OEA, autoridades locais, membros do Processo de Comunidades Negras, de organizações comunitárias daqueles que retornaram ao Naya, de organizações de direitos humanos, da organização indígena $\mathrm{CRIC}_{1}{ }^{3}$ intelectuais, jornalistas regionais e uma das duas emissoras privadas de TV. Enfim, uma variada amostra de governo e sociedade civil. Essa comemoração, a sétima após os acontecimentos de violência, se daria em torno do compromisso do governo em considerar esse povoado como um dos exemplos de reparação econômica e simbólica pelo massacre.

Não obstante seu papel marginal, os integrantes do cabildo indígena autodenominado Kitek Kiwe prosseguiam no seu empenho em preparar o evento: Lisinia, a dirigente nasa que representou as viúvas desse massacre em várias ocasiões, apressava-se porque "não encontro as fotos das vítimas", "não sei onde as guardei desde a marcha de Bogotá em março [2008]". Enquanto isso, os meninos da escola e um dos professores passavam dias ensaiando a apresentação de um sociodrama sobre a sua versão dos fatos. Vimos como corrigiam uns aos outros: "digam vítimas, não mortos!", foi enfática uma menina. Já na comemoração, os Kitek Kiwe abriram o ato de maneira surpreendente, com a entrada das crianças da comunidade por entre o público presente, cantando o hino nacional em língua nasa yuwe. Tomaram conta do cenário e a uma só voz gritaram: "A gente vive, a gente sente, o Naya está presente. Os familiares das vítimas do Naya exigem justiça, verdade, reparação e garantia de não repetição". Cerca de mil espectadores, surpresos, levantaram-se e escutaram em silêncio o hino nacional, entoado nas duas línguas, espanhol e nasa yuwe. Viram impressionados como as crianças agitavam os bastões de mando que simbolizam a autoridade indígena dessa região. As crianças não saíram mais de cena. Ali permaneceram durante horas, no calor intenso das planícies do norte caucano, cercados, literalmente, de faixas e bandeiras que pediam justiça, verdade e reparação para as vítimas do Naya, até encenarem o sociodrama (ver Jimeno, Castillo e Varela 2009). 
Foi assim que o evento se desviou do seu propósito inicial - um ato encabeçado pela comissão governamental encarregada da aplicação da Lei de Justiça e Paz - e chegou à tomada da palavra pelas organizações indígenas e negras. A reparação pela via governamental passou para um segundo plano. Os delegados do governo nacional e local viram-se envolvidos por uma lógica cênica que colocou o clima emocional do evento nas mãos das vítimas do massacre, engendrando a audiência ao redor de símbolos de fácil compreensão e enorme eficácia emocional, como o hino em duas línguas e a versão dos fatos por meio do sociodrama encenado pelas crianças de Kitek Kiwe. Como conseguem engendrar e entusiasmar uma plateia tão heterogênea? Será nativismo e saudade? Como essas encenações deixam para trás a suposta passividade das vítimas para esgrimir por reivindicações muito concretas perante o Estado?

Em abril de 2009, fomos à nova comemoração. O cenário era bem diferente: os Kitek Kiwe tinham decidido realizá-la na sede da comunidade, no terreno que ganharam por meio de uma ação jurídica de tutela. ${ }^{4} \mathrm{O}$ terreno situa-se a poucos minutos da capital regional, a cidade de Popayán, sendo o acesso, portanto, relativamente fácil. Convidaram delegados daqueles que retornaram ao Naya - negros, indígenas, camponeses - e também um grupo seleto de funcionários de governo, organizações internacionais e não governamentais. Mas, nessa ocasião, os convidados centrais eram os fiscais regionais e o fiscal que tem jurisdição sobre o caso do Naya, bem como os procuradores regionais. A entrada para o terreno, debaixo de um arco de fitas verdes e balões brancos e roxos, estava franqueada pela guarda indígena, instituição criada pelo CRIC há cerca de dez anos para fazer "resistência civil"5 aos armados. Arrumados, com casacos novos, portavam as insígnias vermelhas e verdes do CRIC: indicaram que deveríamos nos inscrever a poucos metros da entrada. Em uma escrivaninha improvisada de madeira, quatro meninas anotavam os dados do público em listas que o Cabildo Kitek Kiwe esquematizara. Nos colocaram duas pequenas fitas, uma roxa e outra branca. Subimos até o salão principal da escola.

O salão estava cheio de pessoas da comunidade e de convidados. $\mathrm{O}$ ato era conduzido pela presidente do CRIC naquele momento, a "conselheira-mor" Aida Quilcué. Nas laterais tomaram assento os delegados da Unidade de Justiça e Paz da Fiscalização Geral da Nação, o defensor do Povo do Cauca, funcionários da Procuradoria e o fiscal encarregado da 
investigação pelo massacre no Naya, bem debaixo de faixas enormes: "Pela defesa da vida e a dignidade dos povos"; "Não à impunidade, nem perdão nem esquecimento, castigo aos responsáveis materiais e intelectuais". Ao lado das faixas reproduzidas muitas vezes, seis fotos ampliadas de alguns dos falecidos, ao menos 42 pessoas, em sua maioria homens. Cartazes feitos pelas crianças da escola cercavam o salão.

Um dos dirigentes de Kitek Kiwe dizia: "[...] Isso é o que nós reclamamos como vítimas, [é saber] o que a Fiscalização fez a respeito disso [...]". Em seguida, interveio um camponês que voltou ao Naya:

A mim coube ver como jogavam os corpos nos rios. Se o rio La Balsa falasse... Quanta coisa ele diria! [...] Não entendo por que hoje, quando as vítimas vão reclamar seus direitos em cenários nacionais e internacionais, o governo se queixa! Dizem que falamos muito, que exageramos [...]. Quero criticar muito os direitos das vítimas nas audiências públicas [contra os chefes paramilitares]. Nossa defesa deve ser mais bem garantida a nós, as vítimas [...].

Prosseguiram vários integrantes de associações de vítimas e o evento desembocou numa representação dos "direitos das vítimas", preparado por um grupo do Cabildo Kitek Kiwe: a Dona Verdade, o Senhor Vítima, a Dona Reparação e a Dona Garantia de Não Repetição, encarnados por três mulheres e o jovem governador do Cabildo Kitek Kiwe. Os quatro falavam entre si, preocupados em esclarecer a verdade sobre o que se passou. O Senhor Vítima, representado pelo governador do cabildo, e um dos professores da escola, ficaram de costas para o público, de frente para "as Senhoras Direitos das Vítimas". O Senhor Vítima disse: "Dona Justiça, como vítima, como faço para ter acesso à justiça?". Perguntou um a um a cada um dos direitos como deveria fazer para garantir que suas demandas fossem cumpridas. Os direitos responderam que duvidavam que no governo de Álvaro Uribe seus direitos fossem garantidos. "Mas não há nada que se possa fazer? O que é que eu posso fazer, me ajudem!", exclamava o Senhor Vítima. Os direitos retrucaram: "Se houvesse alguém do governo que se comprometesse... Talvez a situação melhorasse". "A quem devemos recorrer?", "A Fiscalização está aqui?", exclamou o Senhor Vítima. "Sim!", irromperam os presentes. Prosseguiu o Senhor Vítima: "O que me dizem? Fazemos minga?"' , "Sim!", devolveu o público. "O que me dizem? Que a Fiscalização assine o documento?", "Sim!", gritou o público. Os três fiscais presentes ${ }^{7}$ levantaram-se de seus assentos, atordoados pela gritaria repentina. "Está aqui a Defensoria [do Povo]?", "Sim!", retrucava o público. Os defensores presentes ficaram de pé, em silêncio. E "há alguém da Procuradoria?", continuou o Senhor Vítima. 
"Sim!!!", aclamou o público. "Vamos fazer minga de esclarecimento!"; "Quem quer fazer minga?", continuou. "Senhor defensor do Povo, senhor fiscal, comprometem-se a esclarecer o massacre do Naya e garantir os direitos das vítimas?" "Comprometam-se!", gritou o público; "Assinam esta ata de compromisso, juram perante as vítimas, as crianças, as viúvas?". Com os delegados das três instituições de pé: "Assinem!", "Jurem!", bradaram os presentes, agora todos de pé. O Senhor Vítima virou-se para o público: "devem assinar, certo?". "Assinem, assinem!", ressoou o recinto. O defensor do Povo do Cauca levantou a mão direita e, entrecortado: "eu juro". E um após o outro, os demais funcionários o seguiram no juramento e na assinatura de um documento. "Ata" foi como o chamaram os de Kitek Kiwe. Aplausos. Muitos dos presentes se acotovelaram, cercaram os subscreventes, gritando; outros tiravam fotos e gravavam vídeos. Foi o clímax.

Disse o governador do cabildo:

Agora vou fazer uma homenagem simples a uma mulher que é modelo de resistência, modelo de luta que se encerra em duas palavras: "É possível"! É uma homenagem muito simples, muito humilde, para que a senhora continue sendo a voz deste processo, porque as vítimas precisam de vozes como a da senhora. Venha companheira, conselheira Aída Quilcue.

A Conselheira do CRIC recebe presentes das mãos de mulheres do cabildo: um chapéu "com as cores nacionais, uma pulseira para que seu ímpeto não esmoreça e um colar que simboliza as vítimas do alto Naya". Ela respondeu em nasa yuwe e disse em espanhol:

[...] Quero começar hoje lembrando da Cacique Gaitana e sua luta com cinco mil nasas que morreram em Tierradentro [referindo-se à luta de conquista do domínio espanhol no século XVII]. Depois desse primeiro, seguiram-se mais massacres. A razão de tudo isso é que hoje trilhamos a palavra. Trilhamos a palavra em minga, para exigir respeito. Começamos a minga [no ano passado] com muitos assassinatos no norte do Cauca. Surge [então] o atentado contra meu marido. ${ }^{8}$ Não conseguiram desmentir o atentado [...] que pretendia ser mais um dos falsos positivos! $!^{9}$ Não basta a investigação, precisam parar com os assassinatos da comunidade! O que devemos fazer para que deixem de nos matar? [...] Eu queria fazer um chamado às comunidades afro-colombianas para continuarem trabalhando. Vamos nos fortalecer para pedir respeito à dignidade dos povos. Isto precisa ser colhido e transformado em minga, para que se possa gritar com mais força que a dignidade de todos os povos deve ser respeitada. 
E finalizou seu discurso com os passos para recorrer à Corte Penal Internacional por crimes de Estado. Esta representação executada por ocasião da comemoração do massacre de 2001 apropria-se de maneira peculiar da noção de vítima como categoria de negociação frente à institucionalidade. Como se enlaça esta política indígena com um movimento nacional? Até aqui ficou claro que este grupo recorre à etnicidade indígena e opera em nome da profundidade histórica para interpelar os não índios e o Estado por direitos vulnerados. Também fica claro que os índios buscavam um lugar mais equitativo na sociedade nacional e, para consegui-lo, criam símbolos e linguagens novos, recorrendo, entre outros, a encenações - performance, como eles chamam - baseadas numa comunicação eminentemente emocional. É curioso que eles não se limitem à sua própria reclamação de alteridade, mas interpelem a sociedade nacional mediante a incorporação da categoria de vítima, o que lhes permite consolidar a ação política reivindicativa.

Por outro lado, o caso particular do Cabildo Kitek Kiwe representa um movimento cívico mais extenso e pode ser visto como microcosmo que revela tendências sociais mais amplas: a existência de setores heterogêneos da sociedade colombiana, pois alguns são rurais e outros urbanos, pertencendo a setores populares e a camadas médias da sociedade, à esquerda, mas também ao centro político. Alguns são individualidades e outros estão organizados em agrupamentos de vítimas. Entendem-se entre si ao afirmar seus direitos mediante o compartilhamento público de sua experiência com a violência. Sua ação testemunhal é um ato político, com o que transcendem o fato de serem meros depositários ou aspirantes a direitos e benefícios institucionais. Na prática, são uma resposta à demanda de analistas e organizações internacionais que afirmam que na Colômbia não foi designada representação às vítimas e não foram promovidos os seus direitos (informe do International Crisis Group 2008; Uprimmy e Saffon 2006; Casas-Casas e Herrera, documento em preparação).

Interessa-me sublinhar a dimensão político-cultural de quem busca provocar um processo de apropriação compartilhada dos acontecimentos de violência. Por esta via, os movimentos de vítimas transcendem a ideia estabelecida sobre sua passividade e agenciam a sua própria participação em uma tentativa de romper as barreiras - legais, institucionais, de interesses criados - a respeito do seu reconhecimento e reparação. Seu mecanismo central é o uso de uma linguagem emocional, que relata histórias pessoais, narra com detalhes acontecimentos, assinala agentes do crime, distingue quem é a vítima e quem é o algoz, demanda direitos, tudo cerzido pela identificação emocional com a vítima. 
A linguagem emocional não é, evidentemente, natural, espontânea, nem alheia à racionalidade ou ao arrazoamento, como discutirei a seguir. Interessa-me, por ora, chamar a atenção sobre sua qualidade comunicativa, suscitada pelos significados culturais sobre a dor, profundamente incorporados. É possível que assim se possa chegar à verdade social — talvez não à jurídica - ainda tão esquiva. E, diante de tudo isso, pode ser fonte de comunidades morais e cívicas duradouras, que criem laços frente à violência na fragmentada sociedade civil colombiana. Foi por isso que Lisinia, do Cabildo Kitek Kiwe, marchou em Bogotá ao lado de milhares de manifestantes nas grandes mobilizações de 2008 com uma faixa que lembrava as viúvas do massacre do Naya e todas as mulheres que perderam seus maridos em conflitos. Lisinia conta e reconta seu caso nos congressos de vítimas e se indignou na $T V$, chegando às lágrimas, pela extradição do chefe paramilitar H.H., ${ }^{10}$ principal responsável pelo massacre do Naya. Quando fala, é possível nos identificarmos com a sua dor e também com o seu empenho em estabelecer a verdade.

\section{Marchas}

"O ano em que a Colômbia marchou" foi a manchete de El Tiempo ${ }^{11}$ no dia 29 de dezembro de 2008, detendo-se no que considerou fato e personagem do ano: "Quatro marchas em 2008 converteram-se em símbolo de uma Colômbia que deixou de lado a indiferença. Por meio de convocações civis, centenas de milhares de pessoas saíram às ruas para reagir contra a violência, o sequestro e a barbárie" (El Tiempo, 29 de dezembro de 2008:1-8). 4 de fevereiro: "contra o sequestro e as FARC", ${ }^{12} 6$ de março: "Em homenagem às vítimas de paramilitares e crimes de Estado", 20 de julho: "Pelos sequestrados, a poucos dias da Operação Jaque", ${ }^{13}$ e 28 de novembro: "Unidos pela vida e pela liberdade". Continuou o jornal, "Uma Colômbia que faz da dor de alguns a dor de muitos é, provavelmente, o principal legado de 2008, o ano em que as pessoas saíram às ruas para repudiar a barbárie, viesse de onde fosse", continuou El Tiempo (ibid.). Numa coluna ao lado, Iván Cepe$\mathrm{da}^{14}$ acrescentou que, apesar dos contraditores e inclusive das ameaças aos organizadores da marcha do dia 6 de março, "Pela primeira vez o país falou de outras vítimas". "Os rostos dos filhos, das mães e dos irmãos estiveram na retina do país".

Abdón Espinosa Valderrama, ${ }^{15}$ em sua coluna "Espuma dos acontecimentos" (El Tiempo, 7 de fevereiro de 2008:1-21) e, nesse mesmo dia, Rafael Pardo Rueda ${ }^{16}$ (ibid.) mostraram seu entusiasmo em relação à primeira 
marcha, do dia 4 de fevereiro. Pardo destacou que "os partidos assim, fossem eles uribistas ou não, foram superados pelas pessoas [...] as pessoas saíram sozinhas, na prática autoconvocada [...] para esta manifestação sem precedentes de unidade dos colombianos" (ibid.). Abdón falou da "grandiosa marcha de 4 de fevereiro, data já inscrita nos anais da história" e indagava quais seriam os elementos da consciência coletiva que se soube tocar para "suscitar tamanha mobilização popular".

Milhões de pessoas, com efeito, surpreenderam os céticos e desafiaram o tão empregado mote da "indiferença" do colombiano frente à violência. As manchetes de El Tiempo ao longo de 2008 afirmaram que era "Algo jamais visto. Milhões de pessoas marcharam ontem [4 de fevereiro de 2008] no país e no mundo contra as FARC"; "Histórico. O país nunca testemunhara uma manifestação dessa magnitude. Supera a encabeçada por Jorge Eliécer Gaitán ${ }^{17}$ em 1948 e as de 'Nunca mais' à violência, em 1998 e 1999" (El Tiempo, 5 de fevereiro, primera página). "Não se sabe ao certo quanta gente marchou, mas estas imagens [praças e ruas tomadas em várias cidades do país] evidenciam um marco histórico. Nas praças não cabia mais uma alma [...]". "Mais colombianos do que nunca clamaram contra o sequestro e pela paz"; "Outro 20 de julho que passará para a história" (El Tiempo, 21 de julho: primeira página). ${ }^{18}$

Com efeito, as marchas provocaram sentimentos de unidade frente à violência e de esperança na ação cívica. Mas não só incitaram sentimentos, elas também deram lugar a discussões sobre a violência das últimas décadas: novamente apareceu o discurso da autoflagelação, tão adotado na Colômbia: o que fala de "uma sociedade doente", "ausente", "indiferente", de uma condição histórica recorrente, de uma entranha moral perversa do colombiano.

Outros, em contraste, destacaram "o despertar da sociedade civil", que "a demonstração de civismo foi exemplar" ou o papel dos jovens (ibid.). Alguns ainda menosprezaram uma marcha e viram em outra a "verdadeira". Carlos Lozano, diretor do jornal $\mathrm{Voz}_{1}{ }^{19}$ declarou que "A marcha [do dia 4 de fevereiro] amanhã será história antiga, não será ponto de referência para o que deve ser o país" (El Tiempo, 5 de fevereiro:1-5). Vozes ainda mais radicais reduziram cada demonstração a uma manipulação, ora do governo e "dos meios", ora da guerrilha ou dos paramilitares. Os melhores exemplos foram a desqualificação de José Obdulio Gaviria ${ }^{20}$ à marcha de março por ser "pró-guerrilha", dado que falava de crimes de Estado, e os grafites na Universidade Nacional que condenavam a de 4 de fevereiro por ser "paraca". ${ }^{21}$

Mas, em conjunto, proporcionaram a ocasião para que se formulasse a seguinte pergunta: as mobilizações eram mostras de uma ética civil em construção? No dia seguinte à marcha de fevereiro, Mauricio García 
(professor universitário constitucionalista e conhecido colunista) escreveu que se distanciava das apreciações de alguns dos seus amigos contrários à marcha, pois "as marchas que apontam com nome próprio o algoz - em vez de marchar contra 'a violência que nos afeta' - fortalecem a sociedade civil, dão a ela autonomia, voz própria e, por fim, podem criar um reduto ético capaz de mobilizar as pessoas contra todo tipo de violência" (El Tiempo, 5 de fevereiro:1-17). O colunista Álvaro Delgado, em El Tiempo de 27 de julho de 2008, observou que as marchas evidenciavam uma mudança nas formas de protesto social e deixavam para trás "o discurso insurgente da velha esquerda": "Essa população em marcha contou ao país que estava afetada pelo conflito e era vítima de todos os seus promotores: paramilitares, guerrilheiros, forças armadas oficiais" (El Tiempo, 27 de julho:3). Do lado do artigo, por toda a extensão da página, uma foto mostrava uma compridíssima bandeira da Colômbia sustentada por milhares de pessoas em marcha.

As marchas de abril, março, julho e novembro de 2008 tiveram como contraste a indígena de outubro e novembro. Em outubro de 2008, quarenta mil indígenas caminharam de forma organizada a partir da reserva de $\mathrm{La}$ María (Cauca), no sul ocidente, até Cali. ${ }^{22}$ Vinte mil deles chegaram até Bogotá, com o objetivo de expressar ao presidente os seus problemas. Foi a chamada "Marcha pela dignidade dos povos". Não foi, contudo, uma marcha que invocava as vítimas, e nem os indígenas se apresentaram dessa maneira. Conseguiram sim, mais uma vez, chamar a atenção do país em torno de uma nova "Minga pela vida e contra a violência", como a que já tinham organizado em 2002. Em anos anteriores, os indígenas do Cauca tinham se convertido em exemplo de resistência civil contra os armados. "Decidem resistir até o fim". "Cauca — 'Ainda que acabem com nossos povoados, continuaremos de pé', dizem os indígenas", era a manchete de El Tiempo do dia 26 de julho de 2002 (El Tiempo, 26 de julho:1-2). "Os 700 mil indígenas do Cauca começaram a se abastecer e a conseguir lençóis e remédios para enfrentar a arremetida das FARC. Inclusive reviveram a instituição do escambo", continuou o jornal, que incluiu um pronunciamento, " [...] dizemos à Colômbia que os nossos territórios estão cansados de receber tanto sangue injustamente derramado [...]" (ibid.).

Desde 1999, como registra o pesquisador Ricardo Peñaranda (2004), os indígenas do Cauca optaram por demarcar campo abertamente com as organizações armadas ilegais. Foi tão grande a ressonância daquela ação decidida contra uma coluna das FARC que infiltrara uma mobilização de reivindicação indígena nesse ano, que o jornal El Tiempo escreveu, "O que não puderam fazer os paramilitares nem o Estado, os indígenas do Cauca fizeram" (Peñaranda 2004:547): expulsaram as FARC da marcha. 
Poucos anos mais tarde, em maio de 2001, trinta mil indígenas marcharam da cidade de Popayán até Cali, na marcha que chamaram "Minga pela vida e contra a violência", em protesto contra o massacre no alto rio Naya. Nesse momento, os indígenas invocavam expressamente a resistência civil contra os armados e por vários anos fizeram deste conceito seu lema para diversas mobilizações massivas. Peñaranda lista mais de vinte mobilizações entre 1999 e 2004 contra o sequestro de dirigentes e frente a tentativas de invasão de vários povoados do Cauca. Mas depois do massacre do Naya (2001), a resistência civil cedeu lugar à reivindicação como vítimas da violência.

É, portanto, claro que na rejeição à ingerência dos grupos armados em suas comunidades e organizações, os indígenas foram pioneiros, como também na adoção da categoria de vítima como expressão emblemática de experiências de violência e de reivindicação por verdade, justiça e reparação. Minoritários na sociedade colombiana, os indígenas atuam à maneira dos emergentes nos grupos sociais, que expressam primeiro e mais abertamente o mal-estar do conjunto. Mas, além disso, têm a tenaz persistência de quem se reconhece como sobrevivente de muitas batalhas: apesar de mais de cem mortes nesta década, se negam a ceder à pressão armada e dizem como Lisinia, "Se nos matam calados, que nos matem falando".

Em 2009, presenciamos uma novidade nas mobilizações: em vez de passeatas massivas surgiram caminhantes individuais: um menino de doze anos e uma mulher mais velha, de novo o professor Moncayo ${ }^{23}$ pediram a liberação de seu pai, de seus filhos sequestrados pelas FARC. Em julho foi "a mãe que caminhou 570 quilômetros por seu filho", sequestrado pelas FARC há dez anos (El Tiempo, 17 de julho, primeira página). Oliva Solarte, "com sessenta e alguns anos e muitas dores", disse El Tiempo (18 de julho:1-5), caminhou de Gamarra (Cesar) até Bogotá, como fizera de 2007 a 2009 o professor de escola secundária Gustavo Moncayo por seu filho, ${ }^{24}$ em situação semelhante. Grupos espontâneos alentaram Oliva na sua caminhada, que recebeu "a solidariedade de todos aqueles que saíram para ver a sua travessia", continuou o jornal.

Os caminhantes individuais reiteram que na sociedade colombiana foi ativada a consciência social sobre o que significaram para milhares de colombianos estas décadas de confrontação. As marchas, os caminhantes avançaram um discurso que a um só tempo fala em primeira pessoa e não se envergonha da sua dor, repudiando abertamente os grupos armados ilegais e reivindicando ao Estado.

Aqueles que assistiram às marchas foram surpreendidos pela heterogeneidade social dos que participaram em termos de faixa de renda, gênero, ocupação, residência ou raça, bem como pela criatividade dos recursos simbólicos e expressivos, que iam desde performances elaboradas por grupos de 
teatro profissional, até cartazes rústicos montados sobre paus, com as fotos de mortos, sequestrados e desaparecidos. Cantos, bordões e rezas. Balões, flores, borboletas, estampas da virgem Maria, fantasias, pombas e bandeiras, muitas e variadas bandeiras da Colômbia. Inclusive uma que se arrastava por quilômetros, abraçando milhares de participantes. Todos parecem indícios do progresso de uma ética civil contra a ação violenta.

\section{A Lei de Vítimas}

No entanto, nem tudo é propício. Em que pesem as mobilizações que se chamaram "históricas", subsistem grandes discrepâncias, o que coloca a questão de que este é um terreno político em disputa. "Chegou, afinal, a hora das vítimas?" perguntou o artigo de Schultze-Kraft e Munévar no final de 2008 (UN Periódico, 9 de novembro de 2008:5). Até essa data, declaram os autores, os paramilitares submetidos à Lei de Justiça e Paz de 2006 tinham confessado 2.700 crimes e dado informação sobre outros 8.700. As autoridades tinham exumado 1.700 cadáveres, e 155.000 pessoas que denunciavam 123.000 crimes tinham se inscrito como vítimas na Unidade de Justiça e Paz da Fiscalização. Schultze-Kraft e Munévar chamam a atenção para a falta de garantias institucionais aos direitos das vítimas, para as possibilidades de repetição de atos de violência e afirmam que "a falta de representação e voz das vítimas na Colômbia é evidente" (ibid.). Acima de tudo, advertem sobre a falta de interesse do governo no assunto, o que se fez cada vez mais evidente em relação à Lei de Vítimas, como veremos.

Em 5 de maio de 2009, entre as 6 da tarde e 10 da noite, mais de sessenta pessoas convidadas passaram pela sessão especial do Senado da República por ocasião do "Dia de solidariedade do Senado da República para com as vítimas". Esta ação pretendeu apoiar a discussão sobre o projeto de lei 157 de 2007, "Pelo qual são baixadas medidas de proteção às vítimas de violações da legislação penal, de normas internacionais de Direitos Humanos e do Direito Internacional Humanitário perpetradas por grupos armados à margem da lei". Esse projeto foi apresentado pelo senador Juan Fernando Cristo no dia $1^{\circ}$ de outubro de 2007, apoiado pela "Bancada do Partido Liberal no Senado da República" e assinado por 18 senadores. ${ }^{25}$ A apresentação da Lei de Vítimas foi precedida por uma jornada chamada "Solidariedade para com as vítimas do conflito colombiano" organizada em julho de 2007, em conjunto entre senadores liberais e a Fundación Víctimas Visibles (Roldán 2007). Nas considerações sobre o Projeto de Lei, lê-se que, nessa sessão de 2007, "Foram escutados testemunhos de diferentes tragédias, massacres, 
assassinatos seletivos, sequestros, deslocamentos forçados, ocupações de povoados [...]" contra "população civil, contra funcionários públicos, contra organizações civis, contra comunidades indígenas e afro-colombianas [...]". O Projeto de Lei tomou como definição de vítima a estabelecida pelo Direito Internacional Humanitário:

Aquelas pessoas que, individual ou coletivamente, tenham sofrido danos, tais como lesões transitórias ou permanentes, que provoquem algum tipo de incapacidade física, psíquica ou sensorial, sofrimento emocional, perda da liberdade, recrutamento forçado de menores, perda financeira, deslocamento forçado ou menosprezo dos seus direitos fundamentais, como consequência de ações ou omissões que constituam uma violação manifesta das normas internacionais de direitos humanos ou uma violação grave do direito internacional humanitário (Artigo 8 do projeto de Lei de Vítimas).

O projeto foi aprovado na Câmara de Representantes em 2008, mas acabou "afundado" nesse mesmo ano pelo governo, argumentando que era "impossível". Ainda assim, não foi a pique, apenas fez água, sustentado por um grupo do Partido Liberal. O dia de solidariedade promovido pelos liberais permitiu que milhares de telespectadores pudessem escutar o testemunho pessoal de um grupo variado de convidados, novamente com o apoio da Fundación Víctimas Visibles ${ }^{26}$ No dia da sessão testemunhal, o Senado não estava lotado. Muitos senadores, em especial os "oficialistas", ${ }^{27}$ estiveram ausentes e outros repetiam o seu habitual movimento pelo recinto ou cochichavam com o vizinho. Não obstante, mulheres de Casanare, de Antioquia, uma Embera-Katía, um jovem que perdeu a perna com uma mina terrestre foram desfiando suas vivências. Um a um, relataram uma morte cruel de um pai, o rapto de uma jovem, o desaparecimento de um filho, um sequestro de anos e anos, o abandono forçado de seus bens. Usaram poemas, discursos elaborados, improvisos, provérbios, acusaram as autoridades, choraram, choraram muito. "Nós, as vítimas", escutava-se sessenta e tantas vezes, "queremos saber a verdade e por isso contamos a nossa verdade a todos".

Os testemunhos deixaram o Governo e a sua base de apoio no Congresso insensíveis. Mas por sua vez a transmissão pela televisão chegou a um público vasto. Provocou mais de trinta notícias e comentários no El Tiempo entre o início e meados de maio de 2009. Graças a isso, a lei não se limitou a um debate apenas entre os políticos. A própria lei pode ser vista como a expressão normativa de um processo paulatino de generalização social do dano causado, que pôde cimentar uma consciência moral sobre o uso da violência em benefício da "política". 
A oposição à Lei de Vítimas também mostra que estão vivos e ativos na sociedade colombiana aqueles que participaram ou alimentaram a confrontação. Evidencia os interesses encontrados, principalmente os dos algozes tentando encobrir os acontecimentos e conservar o proveito conseguido. Alguns analistas, como John Sudarsky (2009), debatem a mobilização cívica na Colômbia. Sudarsky emprega sistemas de medição do capital social e, em particular, a diminuição da participação ativa da cidadania em organizações seculares no período entre 1997 e 2005 . A partir disso, o autor conclui que há uma desmobilização cívica na Colômbia, em certa medida incentivada pelo governo. Além da bastante discutível adoção desse parâmetro como unidade de medida para a participação cívica, outras fontes o contradizem. O acompanhamento minucioso da DATAPAZ do CINEP (2009) sobre o protesto social pela paz entre 1990 e 2008 chega a uma conclusão contrária: uma mobilização social ampla, com ascensão constante entre 1995 e 1999 e "um comportamento oscilante, mas de elevada categoria, entre 2004 e 2008". "As estatísticas do período 1990-2008 na DATAPAZ do CINEP permitem observar que estamos diante de uma expressão social altamente sensível à violência exercida pelos diferentes atores armados" (DATAPAZ 2009:12; ver também Sarmiento Santander 2009). De acordo com essa informação, diversas regiões e setores sociais participaram dos protestos contra a violação de direitos humanos, contra a violência e em favor da paz, pela prestação de serviços públicos, contra políticas públicas consideradas lesivas, em função da carência de moradia e vias adequadas, contra a gestão deficiente de autoridades locais e contra a corrupção. O protesto das vítimas representou 8\% dos atores que se mobilizaram (DATAPAZ 2009:12).

Outros estudiosos, como Casas-Casas e Herrera (documento em elaboração), mostram que, numa pesquisa realizada com vítimas pela Fiscalização Geral da Nação e outras organizações (Rettberg 2008 apud Casas-Casas e Herrera), observou-se que o interesse principal das vítimas está na reparação material, que algumas não querem que a verdade venha a público e a maioria estaria satisfeita em acessar a política social existente. O problema desta abordagem é que ela silencia a ação pública e organizativa de muitos destes sujeitos e os reduz às variadas opiniões individuais, nas quais aparecem apequenados, medrosos e resignados com o mínimo. É bem possível que o termo vítima só adquira estatuto com base na Lei de Justiça e Paz (Lei 975 de 2005) e, nesse sentido, ainda esteja em processo de apropiação social. Mas é impossível desconhecer o avanço no uso social do termo por muitos dos que sofreram violências, tampouco que se converteu em emblema de reivindicação com uma característica peculiar, que lhe permite reunir o subjetivo e de ordem privada, como é a expêriencia de sofrimento, com a 
ação pública, política. Onde mais residiria a ativa participação social de centenas de vítimas nas mobilizações, nos congressos, nas organizações locais, que dão testemunho público e contribuem para conformar uma consciência coletiva? Se fossem tão passivas e anódinas, matariam os dirigentes?

Nos três últimos anos e até fevereiro de 2009, 20 líderes de organizações de vítimas tinham sido assassinados. Segundo El Tiempo, o que Yolanda Izquierdo, Jaime Antonio Gaviria, Benigno Gil, Ana Isabel Gómez e os demais assassinados tinham em comum era o fato de que reivindicavam reparação e verdade nos processos que citam poderosos chefes "paramilitares" e exigem os bens e a informação que esconderam perante a Lei de Justiça e Paz. "Uma vergonha nacional", escreveu Enrique Santos ${ }^{28}$ (El Tiempo, 19 de abril de 2009:1-21), "que eles tenham sido assassinados impunemente, que muitas tenham sido mulheres porque são as sobreviventes e que menos de $5 \%$ das terras tenham sido distribuídas das mãos dos usurpadores. É, evidentemente, uma vergonha".

Mas as mortes e ameaças não calaram as vítimas organizadas. Nem o variado espectro de quem participa do processo de visibilização que se move entre a Fundación Víctimas Visibles, que emprega recursos para convidar, em junho de 2009, os Príncipes de Astúrias para o Congresso de vítimas em Medellin e invocar a imagem de "Santa Maria da Paz", até as Mães da Candelária, o Comitê de Familiares de Vítimas da Violência de Córdoba, o Cabildo Nasa Kitek Kiwe e o CRIC ${ }^{29}$ no Cauca ou a organização de Iván Cepeda contra os crimes de Estado em Bogotá. Parece-me que este processo dos últimos anos é a confluência de agendas, tendências e ênfases muito variadas em torno de um mesmo tema: que rosto têm as vítimas, qual é a sua voz? Quem as atacou, por quê? Teremos verdade, justiça, reparação? É, portanto, a vítima como categoria política.

\section{Conclusões: a linguagem emocional como discurso político}

Escrevi diversas vezes, com tenaz insistência, que nós, os colombianos, costumamos pensar que somos caracterizados como um povo violento, com uma história ininterrupta de violência. Essa autopercepção está fortemente enraizada, chegando ao ponto de ter se tornado uma identidade negativa, com repercussões sobre a cultura política e, evidentemente, sobre a ação política (Jimeno 1998). Este me parece um traço cultural, não no sentido de que exista alguma coisa que possamos denominar "cultura da violência", mas no sentido de que aprendemos a nos reconhecer assim, que damos isso por certo, sem questionar, e que muitas das nossas apreciações sobre 
a vida social e muitos dos nossos comportamentos e práticas cotidianos se orientam por esse pressuposto. Muitos discursos do cotidiano, assim como dos círculos de especialistas, têm em comum o fato de se referirem reiteradamente a essa entranha malvada e atribuí-la às mais variadas razões e sem razões. A crença de que somos um povo violento faz, portanto, parte de um repertório compartilhado, ou de uma lente através da qual olhamos o entorno, e, nesse sentido, é cultural. Como costuma acontecer com as crenças, elas se sustentam sobre uma rede de evidências de pressupostos tácitos que as retroalimentam e as confirmam como conhecimento dado. Cada fato de violência confirma a crença, mas os que a refutam, matizam ou questionam são desconsiderados ou ignorados.

Pois bem, essa crença ou pressuposto cultural nos leva a negar a possibilidade de progresso cívico na Colômbia. Essa crença sobre a violência que nos acompanharia, qual sombra maligna, faz parte de um pressuposto maior segundo o qual a autoridade não é de se fiar e é temível. Esse pressuposto é muito arraigado, talvez desde quando os liberais radicais ajudaram a construir a ideia de que toda forma de autoridade era uma forma de traição à liberdade, moldando isso numa normatividade que, por sua debilidade, abriu caminho para um modelo de Estado nacional centralizador (Jimeno et alii 1996; Jimeno 1998). Revive-se o exercício de autoridade arbitrária, no seio do lar, estruturando as noções culturais de correção e respeito à autoridade que mediam o maltrato no lar (Jimeno et alii 1996 e 1998).

Em contraste com a firmeza da crença sobre a pretendida inclinação colombiana à violência, a noção de vítima é produto de um processo relativamente recente na Colômbia. Sua apropriação tomou a forma do testemunho pessoal público. As pessoas falam do que sabem, perguntam pelo que querem saber e, acima de tudo, expõem aos olhos públicos sua dor e a recolhem na palavra vítima.

A vítima, como sabemos, se queixa, sofre e pode ficar presa e isolada na dor experimentada. Pode se calar e se ensimesmar no sofrimento. Nesse caso dizemos que produz "lástima". Mas as vítimas que vimos recentemente, como o professor Moncayo ou o menino Yohan Stiven Martínez, fazem um ato público, "trilham a palavra" ao seu modo. Carlo Tognato (Tognato 2009) nos mostra em um recente artigo que, com suas caminhadas pelo país, o professor Moncayo obtém uma convocação inovadora de solidariedade para com os sequestrados, conseguindo forjar nesse ato de solidariedade, ao menos temporariamente, uma sociedade civil fragmentada. Parece-me que alcança essa fusão da sociedade civil porque a categoria de vítima é um mediador simbólico entre a experiência subjetiva e a generalização social. O curioso e interessante dessa mediação é que ela é feita através da convocação de uma 
comunidade emocional e não por meio da invocação de princípios abstratos de direitos violentados. Nesse contexto, o discurso emocional é inclusivo e não particularista, é político e não privado.

Como isso se produz? Giorgio Agamben (2002) chegou à conclusão de que o testemunho pessoal consegue atingir uma verdade que não é a verdade jurídica, fazendo emergir uma luz de entendimento sobre o incompreensível do terror. Gostaria de radicalizar a proposta de Agamben, no sentido de afirmar que o processo que permite sobrepassar a condição de vítima passa pela recomposição do sujeito mediante a expressão manifesta e compartilhada da sua vivência. Mas, para além disso, o testemunho pessoal tem força porque permite a identificação emocional, psicológica, entre pessoas dessemelhantes. Um dos clássicos da antropologia dizia que as categorias emocionais ele pensava na bruxaria entre os Azande do Sudão (Evans-Pritchard 2005 [1937]) — não servem apenas para expressar o infortúnio das pessoas ou das relações pessoais, mas envolvem também juízos morais, e hoje sabemos com Robert Solomon que as emoções são juízos sobre o mundo (Calhoun e Solomon 1996; Castilla del Pino 2003). Assim, a linguagem emocional não é apenas "sentimento", mas um veículo para as relações sociais e também um juízo sobre o mundo. As emoções são, pois, avaliações ou juízos de valor e, nesse sentido, elementos essenciais da inteligência humana, como sustenta Martha Nussbaum (2008).

O sentimento ou a emoção tampouco são categorias naturais ou respostas instintivas. David Le Breton (2009) é feliz em sua colocação de que as lágrimas não são um reflexo da dor, mas revelam uma linguagem que se insere nas convenções que modelam o sentimento por meio de uma sutil dialética. Não adquirimos o vocabulário emocional pela consulta ao dicionário, continua Le Breton, mas este impregna as relações sociais e faz eco no menino que aprende o seu significado ao vê-las encarnadas nos seus próximos (Le Breton 2009:172-173). Em poucas palavras, as emoções são culturais e históricas.

Justamente a natureza emocional da categoria vítima torna possível que divisões ideológicas e sociológicas possam ser recolhidas em um momento antiestrutura - como diria Victor Turner - e, acima de tudo, pode se converter em instrumento político para afiançar a frágil institucionalidade, como é o caso da Lei de Vítimas. É possível que conseguir justiça, e inclusive reparação, ${ }^{30}$ seja algo esquivo na atualidade colombiana. Mas a afirmação e o vigor da vítima fazem parte de um processo social progressivo no sentido da afirmação da sociedade civil frente ao impacto da violência das duas últimas décadas. Essa categoria permite expressar, de forma inédita na Colômbia, os fatos de violência a partir da perspectiva daqueles que a 
sofreram e torna possível articular uma narrativa na qual é possível ventilar sentimentos de dor, raiva e compaixão, como não fizemos na pós-violência dos anos 1950. É decisivo, no entanto, que exista um vínculo que una as emoções com a ação política. A moral cristã está intimamente ligada a certas formas de apreciação e expressão do sentimento de dor e as modelou em nosso entorno. Poderemos construir juízos morais que instituam uma ética civil na política colombiana e transcendam a matriz cristã da dor?

Alguns estudiosos de novas orientações na investigação política (Wood 2001) apontam para a inadequação de reduzir a ação política a uma relação de custo-benefício e probabilidades de êxito. A mobilização política proporciona não apenas informação, mas simpatia, confiança e identificação emocional (Wood 2001:306). Por isso, a categoria vítima, com sentido público compartilhado, é uma categoria da ética civil. Possui uma alta expressividade que dá lugar a comunidades emocionais, políticas, vale dizer, pessoas que na sua radical individualidade, como diria Hannah Arendt (2005), se unem para atuar em torno de objetivos comuns. Este processo ainda pode ser temporário ou efêmero se não se ancora em organizações e ações civis e institucionais, em "empreendedores da memória", como os chama Elizabeth Jelin (2002). Mas é um meio de explorar o sofrido por setores da sociedade nas duas últimas décadas, que aponta para a cura de feridas que ainda não sararam na memória coletiva.

A narrativa que emerge tem efeitos políticos enquanto mediador simbólico entre a experiência subjetiva e a generalização social. É decisiva para as ações de protesto e reparação, mas acima de tudo constrói uma versão compartilhada dos acontecimentos de violência da última década e serve de alicerce para uma ética do reconhecimento.

A categoria vítima parece-me a expressão de uma sociedade que se debateu em silêncio frente à necessidade de falar. Parece significativo que os que tomem a palavra sejam principalmente mulheres e, a seu lado, as minorias indígenas. Do ponto de vista cultural, as mulheres tiveram maior liberdade para expressar suas emoções e conhecem bem a linguagem emocional. Isto foi fonte de juízos pejorativos, que se sustentam sobre a também cultural dualidade entre emoção e razão. Contudo, nesta circunstância do país, elas abriram para todos o caminho do testemunho pessoal como terreno comum, compartilhado, com o qual fechar a brecha entre sujeito, subjetividade e acontecimentos socioculturais (Jimeno 2008:81).

As minorias indígenas muito frequentemente expressaram na Colômbia o que outros calam (ver Ramos 1998) - a recusa do exercício da violência em nome de supostos princípios políticos - e pagaram um alto custo por isso. Sua reivindicação por autonomia e respeito pela cultura "própria" é um 
meio para conseguir um diálogo nacional respeitoso da diferença e permite um terreno comum de encontro e identificação emocional.

Em suma, eu quis propor que as emoções são uma linguagem política, não apenas um sentimento íntimo; esta linguagem, ao ser compartilhada publicamente, possibilita comunidades morais sustentadas pela ética do reconhecimento que alimenta a ação política. A noção de vítima aspira a sintetizar a magnitude do ocorrido e a se converter em símbolo cultural dos sentimentos de dor e raiva de milhares de colombianos. Se esse símbolo consegue a sua generalização (Alexander 2006) e obtém a identificação de amplos setores da sociedade colombiana, teremos encontrado uma forma de compartilhar e de atuar como sociedade no marco da civilidade.

Recebido em 02 de fevereiro de 2010

Aprovado em 23 de abril de 2010

Tradução de Fernanda Guimarães

Myriam Jimeno é professora titular da Universidade Nacional da Colômbia. E-mail: <mjimenos@gmail.com>

\section{Notas}

* Este texto contou com a colaboração dos antropólogos Ángela Castillo e Daniel Varela, co-pesquisadores do projeto "Ciudadanías en el límite. El caso de la comunidad Kitek Kiwe", que desenvolvemos no Cauca com o apoio da Universidade Nacional da Colômbia e da MSD/USAID. Uma versão preliminar foi apresentada no XVI Congresso de Colombianistas, "El progreso en Colombia", Universidade da Virgínia, Charlottesville, Virgínia, 4 a 7 de agosto de 2009. A versão atual foi apresentada como conferência de abertura da II REA/XI ABANNE, de 19 a 22 de agosto de 2009.

${ }^{1}$ De agora em diante, usarei essa palavra em itálico, para ressaltar seu caráter central na construção sociocultural de um conjunto simbólico ao qual acodem deliberadamente certos agentes sociais na sociedade colombiana, incluindo os indígenas, em sua busca por reivindicação. Abstenho-me de assinalar da mesma forma outros conceitos associados, pois subtrairiam sua importância e dificultariam a leitura do texto.

${ }^{2}$ Região encravada nas ramificações ocidentais da Cordilheira dos Andes, no sul ocidental da Colômbia. 
${ }^{3}$ Conselho Regional Indígena do Cauca. Foi criado em 1971 e é a organização regional étnica mais consolidada na Colômbia.

${ }^{4}$ A tutela é um recurso jurídico que uma pessoa pode interpor perante um juiz, de maneira que se cumpra mais depressa um direito considerado fundamental pela Constituição.

${ }^{5}$ As aspas são usadas para indicar que é uma expressão utilizada por eles mesmos.

${ }^{6}$ Palavra usada pelos indígenas de várias regiões para se referirem à formação de um grupo no intuito de se empreender alguma tarefa de interesse comum. Por extensão, é usada para mobilizações ou ações sociais coletivas.

${ }^{7} \mathrm{O}$ fiscal que esteve ali presente pertencia à Unidade de Direitos Humanos da Fiscalização Geral da Nação, seção de Cali. Alguns meses depois, talvez animado por esse ato de compromisso, ordenou colocar na prisão duas altas autoridades do Exército colombiano com jurisdição na região à época do massacre. Pouco tempo depois, o fiscal foi afastado do caso, que passou para as mãos de outro escritório que do de Direitos Humanos. A primeira medida foi declarar a nulidade do processo e pôr em liberdade os militares acusados. Não tardaram a aparecer ameaças contra o fiscal, que precisou se esconder por um tempo, e até os dias de hoje o processo pelo massacre está parado.

${ }^{8}$ Edwin Legarda foi morto em dezembro de 2008 em uma área militar. Alegaram tê-lo confundido com um guerrilheiro.

${ }^{9}$ Esta expressão é usada para indicar civis que foram mortos pelo Exército Nacional, simulando que eram guerrilheiros abatidos em combate. Esse grave ato suscitou um grande escândalo público, já que se estima em cerca de mil o número de vítimas.

${ }^{10}$ Hever Velosa, codinome H. H., foi um dos vários chefes dos "paramilitares" enviados pelo governo da Colômbia à Justiça dos EUA em 2008, em virtude do tratado existente para a extradição de criminosos. Isto foi visto pelas organizações de vítimas como uma maneira de silenciar suas declarações.

${ }^{11}$ Principal jornal de circulação nacional.

${ }^{12}$ Sigla de Forças Armadas Revolucionárias da Colômbia.

${ }^{13}$ Este foi o nome dado pelo Exército colombiano à ação de resgate de um grupo de sequestrados pelas FARC, em 2008, entre os quais estava a ex-candidata presidencial Ingrid Betancourt.

${ }^{14}$ Principal ativista do movimento de vítimas de crimes de Estado: seu pai, dirigente comunista, foi morto nos anos 1990 por "paramilitares", ao que parece com a conivência de agentes estatais. 
${ }^{15}$ Abdón Espinosa é um economista conhecido e colunista há muitos anos. Ocupou cargos de destaque, como o de Ministro da Fazenda em duas ocasiões, nos anos 1960 e 1970 .

${ }^{16}$ Rafael Pardo é atualmente candidato à Presidência da República pelo Partido Liberal. Foi Conselheiro de Paz e Ministro da Defesa nos anos 1990.

${ }^{17}$ Dirigente político e candidato à Presidência da República pelo Partido Liberal, de oposição ao governo naquele momento. Foi assassinado em 1948, pouco depois dessa manifestação. Sua morte acirrou ainda mais o confronto entre os partidos liberal e conservador, tendo como consequência milhares de mortes no período entre 1946 e 1956, conhecido na Colômbia como "A Violência".

${ }^{18}$ Em março de 2009, o mesmo jornal lembrava que o país teve em 2008 três marchas por dia, sendo 424 apenas em Bogotá, incluídas não somente as realizadas contra a violência, mas outras manifestações cívicas de protesto.

${ }^{19}$ Jornal do Partido Comunista Colombiano.

${ }^{20}$ Assessor do presidente Álvaro Uribe, conhecido por suas posições radicais contra os críticos do governo.

${ }^{21}$ Termo coloquial usado para referir-se aos "paramilitares".

${ }^{22}$ Cidade principal do sul ocidental colombiano.

${ }^{23}$ Gustavo Moncayo é um professor de escola secundária numa pequena localidade no sul da Colômbia. Desde 2007 começou a fazer grandes caminhadas pelo país, pedindo que o governo negociasse com as FARC a liberação dos sequestrados, entre os quais estava o seu filho, um jovem policial sequestrado em $1998 \mathrm{em}$ um ataque a um posto de vigilância da polícia.

${ }^{24} \mathrm{O}$ filho do professor Moncayo foi um dos dois policiais liberados pelas FARC em abril de 2010, depois de doze anos de sequestro. É bem provável que o protagonismo de seu pai tenha sido decisivo para que as FARC decidissem unilateralmente por sua liberação.

${ }^{25}$ Juan Fernando Cristo, Héctor Helí Rojas, Luis Fernando Velasco, Jesús Ignacio García V., Cecilia López Montaño, Yolanda Pinto, Juan Manuel Galán, Luis Fernando Duque, Alvaro Asthon, Guillermo Gaviria, Carlos Julio González, Mauricio Jaramillo, Germán Aguirre, Víctor Renán Barco, Mario Salomón Náder, Camilo Sánchez, Hugo Serrano Gómez, Piedad Córdoba Ruiz, Senadores da República.

${ }^{26}$ Esta Fundação é vista com ressalvas pelas organizações de esquerda.

${ }^{27}$ Participantes da coalizão que apoia o presidente Álvaro Uribe. 
${ }^{28}$ Colunista e coproprietário de El Tiempo.

${ }^{29}$ Conselho Regional Indígena do Cauca.

${ }^{30}$ O coordenador da Comissão Nacional de Reparação, Carlos Pizarro, informou no final de 2009 sobre a reparação administrativa a dez mil pessoas na qualidade de vítimas de paramilitares.

\section{Referências bibliográficas}

AGAMBEN, Giorgio. 2002. Lo que queda de Auschwitz. El archivo y el testigo. Valência: Pre-Textos.

ALEXANDER, Jeffrey. 2006. "Cultural pragmatics: social performance between ritual and strategy". In: J. Alexander, G. Bernhard and J. Mast (orgs.), Social performance. Symbolic action, cultural pragamatics, and ritual. Cambridge: Cambridge University Press. pp. 29-90.

ARENDT, Hannah. 2005. La promesa de la política. Barcelona e Buenos Aires: Paidós.

CALHOUN, Cheshire; SOLOMON, Robert. 1996. Qué es una emoción? Lecturas clásicas de psicología filosófica. México: Fondo de Cultura Económica.

CASAS-CASAS, Andrés; HERRERA, Germán. s/d. Lo que quieren las víctimas? Paradojas y retos de la tensión entre el sery el deber ser en el proceso de reparación en Colombia. Bogotá: Facultad de Ciencia Política y Relaciones Internacionales, Pontificia Universidad Javeriana, documento em processo.

CASTILlAS DEL PINO, Carlos. 2003. Teoría de los sentimientos. Barcelona: Tusquets Editores.
CASTILLO, Ángela; JIMENO, Myriam; VARELA, Daniel. 2009. A los siete años de la masacre del Naya. La perspectiva de las víctimas. Rio de Janeiro: Tempo Brasileiro Ltda.

CINEP. 2009. Datapaz. Banco de datos de acciones colectivas por la paz. www. cinep.org.co/node/92.

EVANS-PRITCHARD, Edward. E. 2005 [1937]. Bruxaria, oráculos e magia entre os Azande. Rio de Janeiro: Jorge Zahar Editor.

JELIN, Elizabeth. 2002. Los trabajos de la memoria. Madrid: Siglo XXI Editores.

JIMENO, Myriam. 1998. "Identidad y experiencias cotidianas de violencia". Revista Análisis Político, XXXIII:32-46. . 2008. "Lenguaje, subjetividad y experiencias de violencia". In: F. Ortega (ed.), Veena Das: sujetos del dolor, agentes de dignidad. Bogotá: Universidad Nacional de Colombia, Universidad Javeriana. pp. 261-291. . et alii. 1996. Las sombras arbitrarias. Violencia y autoridad en Colombia. Bogotá: Editorial Universidad Nacional de Colombia. .1998. Violencia cotidiana en la sociedad rural. En una mano el pan y en la otra el rejo. Violencia y autoridad 
en Colombia. Bogotá: Universidad Sergio Arboleda.

INTERNATIONAL CRISIS GROUP. 2008.

"Corregir el curso: las víctimas y la

Ley de Justicia y Paz en Colômbia". Informe sobre América Latina, n. 29-30.

LE BRETON, David. 2009. As paixões ordinárias. Antropologia das emoções. Petrópolis: Vozes.

NUSSBAUM, Martha C. 2008. Paisajes del pensamiento. La inteligencia de las emociones. Barcelona e Buenos Aires: Paidós.

PEÑARANDA, Ricardo. 2004. "Resistencia civil y tradiciones de resistencia en el suroccidente colombiano". In: F Gutiérrez, M. E. Wills e G. Sánchez (orgs.), Nuestra guerra sin nombre. Transformaciones del conflicto en Colombia. Bogotá: Grupo Editorial Norma. pp. 545- 567.

RAMOS, Alcida. 1998. Indigenism. Ethnic politics in Brazil. Madison: The University of Wisconsin Press.

ROLDÁN, Ismael. 2007. Las víctimas civiles del conflicto armado colombiano: hacia la búsqueda de la verdad. Bogotá: Fundación Víctimas Visibles, Escuela de Comunicación y Periodismo, Universidad Sergio Arboleda.

SARMIENTO SANTANDER, Fernando. 2009. Acciones colectivas por la paz en Colombia. DATAPAZ: Reporte enero a marzo de 2005. www.reliefweb. int/library/documents/2005, cinepcol-10jun pdf.

SUDARSKY, John. 2009. "Acontabilidad y representación: la evolución de la relación entre Estado y sociedad desde la perspectiva de la medición del capital social de Colombia con el Barómetro del Capital Social (Barcas), 1997-2005". Comunicação no XVI Congreso de Colombianistas, Charlotteville, agosto de 2009. Mimeo.
TOGNATO, Carlo. (no prelo). "Extending trauma across cultural divides: On kidnapping and solidarity in Colombia." In: J. Alexander, R. Eyerman, E. Breese, Elizabeth (orgs.), Narrating trauma: studies in the contingent impact of collective suffering. Paradigm Publishers.

UPRIMMY, Rodrigo; SAFFON, María Paula. 2006. "La ley de justicia y paz: ¿una garantía de justicia y paz y de no repetición de atrocidades?". In: R. Uprimmy (ed.), Justicia transicional sin transición?: verdad, justicia y reparación para Colombia. Bogotá: DeJusticia. pp. 176-192.

WOOD, Elizabeth Jean. 2001. "The emotional benefits of insurgency in El Salvador". In: J. Goodwin, J. Jaspers e F. Polletta (orgs.), Passionate politics. Emotions and social movements. Chicago: Chicago University Press. pp. 267-281. 


\section{Resumo}

No presente texto, detenho-me na construção cultural da categoria vítima como forma de afirmação da civilidade. Ao longo dos últimos anos, temos presenciado na Colômbia a afirmação de uma linguagem que narra experiências pessoais de sofrimento na forma de testemunho pessoal. Essa linguagem, eminentemente emocional, cria laços entre pessoas diversas, naquilo que podemos chamar sociedade civil, ao redor do compartilhamento da "verdade" a respeito dos fatos de violência ocorridos recentemente. Argumento que esta linguagem do testemunho pessoal tem efeitos políticos, na medida em que constrói uma versão compartilhada dos acontecimentos de violência da última década e serve de alicerce para uma ética do reconhecimento e para ações de protesto e de reparação, visto que é um mediador simbólico entre a experiência subjetiva e a generalização social. Examino a construção social da categoria vítima em três cenários sociais: a encenação e a mobilização por parte da comunidade indígena diante de fatos de violência, as manifestações massivas de 2008 e a luta pela promulgação da Lei de Vítimas. Destaco o papel relevante de mulheres e indígenas ao realizarem testemunhos públicos sobre os fatos de violência, como forma de chegar à verdade, o que aponta para a criação de uma narrativa compartilhada e para a generalização de princípios morais diante dos atos de violência feitos em nome da "política".

Palavras-chave Vítima, Violência, Comunidades emocionais, Colômbia

\section{Abstract}

This text focuses on the cultural construction of the category of victim as an affirmation of civility. Over the last few years Colombia has seen the emergence of a genre of language dedicated to narrating experiences of suffering in the form of personal testimony. This highly emotive language creates bonds between different members of 'civil society' who find common ground in sharing 'the truth' concerning the acts of violence perpetrated in recent years. I argue that the idiom of personal testimony produces political effects since it creates a shared version of the violent events occurring over the last decade. Moreover it opens the way for an ethics based on the recognition of demands for reparation by providing a symbolic mediation between subjective experience and the society at large. I examine the social construction of the category of victim in three different settings: the mobilization of the indigenous community in response to violent acts; the massive protests held in 2008 against these acts; and the campaign for approval of the Victims Law. I also highlight the crucial role played by women and indigenous peoples in testifying publicly about this violence as a way of arriving at the truth, a process leading to the construction of a shared narrative and to the generalization of moral principles vis-à-vis acts of violence perpetrated in the name of 'politics.'

Key words Victim, Violence, Emotional communities, Colombia. 